\title{
A IMPORTÂNCIA DO PLANEJAMENTO FINANCEIRO EM TEMPOS DE CRISE ECONÔMICA
}

Neuza Dias Franco, Reinaldo de Oliveira Nocchi

Universidade do Oeste Paulista - UNOESTE, MBA em Finanças e Controladoria, Presidente Prudente, SP. E-mail: neuzadiasfranco@bol.com.br

\section{RESUMO}

Planejamento refere-se ao efeito de planejar; e planejamento financeiro é relativo às finanças, à circulação e gestão do dinheiro e outros recursos líquidos. O assunto de finanças é amplo e complexo, porque afeta a vida das pessoas e organizações, todos obtêm ou levantam fundos, gastam ou investem. Este trabalho tem como objetivo consolidar o papel e a importância do planejamento financeiro junto à organização para se preparar e superar crises. Na atualidade, fazse cada vez mais necessária a aplicação de metodologias de planejamento financeiro nas empresas, considerando que estão inseridas em um mundo globalizado onde as mudanças tecnológicas e o dinamismo da economia estão em ritmos mais acelerados. A metodologia aplicada foi de pesquisa bibliográfica, contemplando pesquisas em revistas, livros e estudos sobre planejamento financeiro. Os resultados encontrados mostram que o planejamento financeiro é fator determinante no desempenho das empresas e indispensável para a permanência das mesmas no mercado.

Palavras-chave: finanças, administração, controladoria.

\section{THE IMPORTANCE OF FINANCIAL PLANNING IN TIMES OF ECONOMIC CRISIS}

\begin{abstract}
Planning refers to the effect of planning; And financial planning is relative to finance, circulation and management of money and other net resources. The subject of finance is broad and complex, because it affects the lives of people and organizations, everyone gets or raises funds, spends or invests. This paper aims to consolidate the role and importance of financial planning with the organization to prepare for and overcome crises. At present, it is increasingly necessary to apply financial planning methodologies in companies, considering that they are inserted in a globalized world where the technological changes and the dynamism of the economy are at faster rates. The applied methodology was of bibliographical research, contemplating researches in magazines, books and studies on financial planning. The results show that financial planning is a determining factor in the performance of companies and indispensable for their permanence in the market.
\end{abstract}

Keywords: finances, administration, controller.

\section{INTRODUÇÃO}

A gestão financeira refere-se ao processo de obtenção e aplicação de recursos financeiros que possibilitem à empresa atingir e manter o seu nível de atividade desejada, além disso, trata da administração das finanças da empresa que integra todo trabalho ligado à obtenção, utilização e controle destes recursos. O resultado do modelo de gestão, a organização da estrutura e o planejamento dos sistemas de informações reflete a eficiência que uma empresa busca atingir.

Atualmente, a gestão financeira é uma das áreas mais importantes e críticas da análise de desempenho de uma empresa, ou seja, entender estes comportamentos e atuar sobre as causas desses problemas. Compreende-se como modelo de gestão, a administração que influenciará na tomada de decisão. Para tomada de uma decisão, o gestor financeiro terá que coletar os dados 
financeiros junto ao contador e por meio de certos ajustes e análises precisa enxergar além das demonstrações financeiras, para perceber problemas que estão surgindo ou existem.

A gestão financeira está estritamente ligada à contabilidade para evitar situações de desconforto financeiro e para que a organização esteja apta para tomada de decisões com base em informações confiáveis. O planejamento financeiro é essencial para o sucesso empresarial e pessoal, tendo em vista que apenas com organização e perspicácia é possível driblar as adversidades e conquistar objetivos, além do ganho de vantagem competitiva, crescimento, melhoria interna, otimização de processos, promoção da capacitação, identificação de oportunidades e construção de estratégias conjuntas, visando ao crescimento e sustentabilidade.

Muitas empresas não realizam este planejamento e diante das adversidades surgem problemas sérios na organização. Com o planejamento é possível prever esses problemas, antes mesmo que assombrem a empresa, e assim o empresário terá tempo para analisar e se preparar para qualquer crise. O planejamento tem se tornado imprescindível na vida das empresas contemporâneas. Isso tem permitido efeitos reais de produção de resultados desejados, como no campo da gestão de organizações com fins lucrativos. Em situações de gestão de organizações, como lugar de produção, predomina a lógica que articula a relação entre meios e fins, tornando os fins dados como perseguíveis instrumentalmente na busca de maior otimização dos recursos.

O assunto de finanças amplo e complexo, afeta a vida das pessoas e organizações, pois todos obtêm ou levantam fundos, gastam ou investem. A empresa, vista como uma organização complexa deve-se ter um modelo de gestão, um processo de planejamento e controle e um sistema de informações, que se inter-relacionam buscando atingir a eficácia. A sobrevivência e o crescimento são consequências de um planejamento financeiro que envolve um eficiente orçamento, controle das receitas e despesas e que seja suficiente para a projeção de um fluxo de caixa e consequentemente um melhor controle dos recursos financeiros, garantindo assim a viabilidade e a permanência da empresa no mercado.

Entretanto, por diversos motivos, a maioria destas empresas não tem obtido sucesso ao longo de sua existência, caminhando para a descontinuidade de maneira precoce. E entre os motivos, a ausência de planejamento financeiro tem destaque. Todos querem ter seu próprio negócio, mas poucos se preocupam com as regras básicas da abertura e administração.

$\mathrm{Na}$ maioria das micro e pequenas empresas encontramos uma má administração dos recursos financeiros. Os empresários ainda não têm uma mentalidade voltada para o planejamento, isso dificulta a sobrevivência da empresa, pois normalmente não possuem grandes reservas de capital e ao se deparar com as primeiras dificuldades acabam caindo pelo despreparo.

De acordo com Sebrae, abordando como referência as empresas brasileiras constituídas em 2012, e as informações disponíveis na SRF até 2014, a taxa de sobrevivência das empresas com dois anos de atividades foi de $76,6 \%$, sendo essa a maior taxa de empresas com até dois anos.

Diante disso, o presente estudo tem como objetivo perceber, através de conceitos teóricos e práticos, o papel e a importância do planejamento financeiro junto à organização para se preparar e superar crises.

\section{METODOLOGIA}

A metodologia adotada baseou-se em revisão bibliográfica, contemplando pesquisas em revistas, livros e estudos já desenvolvidos sobre planejamento financeiro.

A pesquisa bibliográfica procura explicar um problema através de referências bibliográficas buscando conhecer e analisar as contribuições culturais e científicas, conforme Cervo e Bervian (2002). A pesquisa bibliográfica também identifica os problemas mais comumente enfrentados pelos gestores financeiros das organizações, e como eles foram solucionados ou tiveram seus reflexos minimizados, no âmbito da gestão de recursos financeiros. 


\section{RESULTADOS E DISCUSSÃO}

Os resultados encontrados mostram que o planejamento financeiro é fator determinante no desempenho das micro e pequenas empresas. A expressão planejamento é definida como o ato ou efeito de planejar, ou seja, o trabalho de preparação para qualquer empreendimento, seguindo roteiros e métodos determinados; planificação, processo que leva ao estabelecimento de um conjunto coordenado de ações (pelo governo, pela direção de uma empresa, entre outros), visando à obtenção de objetivos determinados; elaboração de planos ou programas governamentais, especialmente na área econômica e social. Já financeiro significa, relativo às finanças, à circulação e gestão do dinheiro e outros recursos líquidos. O planejamento financeiro tem-se a junção desses dois conceitos levados para um plano empresarial (LUCION, 2005).

Diante de um cenário de crise em que nos encontramos, para que uma organização possa sobreviver e manter-se num mercado onde o que prevalece é a alta competitividade, é necessário que o administrador tome suas decisões em informações que possua qualidade e atualização. É necessário se organizar e planejar para que a empresa permaneça no mercado e possua materiais para fazer circular bens e serviços, gerando riquezas.

Segundo Chiavenato (2003), o mundo em que vivemos é uma sociedade institucionalizada e composta por organizações. Todas as atividades relacionadas à produção de bens ou prestação de serviços são planejadas, coordenadas, dirigidas, executadas e controladas pelas organizações. Todas as organizações são constituídas por pessoas e por recursos não humanos (recursos físicos e materiais, financeiros, tecnológicos, mercadológicos). A vida das pessoas depende intimamente das organizações e essas dependem da atividade e do trabalho daquelas.

A economia sofre variações e encontra-se vulnerável a fatores globais, dessa forma, o plano financeiro empresarial tende a ser mais valorizado e apreciado em primeiro plano no momento de se tomar uma decisão. Segundo Gitman (1997, p.588), "as empresas utilizam-se de planos financeiros para direcionar suas ações com vistas a atingir seus objetivos imediatos e a longo prazo onde um grande montante de recursos está envolvido". Para a sobrevivência de uma empresa é imprescindível uma boa administração de todos os recursos de produção e circulação de bens e serviços para sua saúde eficaz.

Dentro deste cenário, iniciativas ligadas à produtividade tornam-se fundamentais para o crescimento e gerenciamento de eventuais crises e obtenção dos resultados visados pela empresa e seus dirigentes. A questão é: como fazer para superar desafios? Que mecanismos usar para atingir os objetivos?

A busca pela conquista de melhores resultados depende de uma série de fatores. A administração financeira tem sido considerada como uma das cinco grandes áreas, ao lado da administração de pessoal, de compras, de marketing e da produção. A administração financeira partilha com outras áreas as funções básicas de: planejar, organizar, coordenar, dirigir e controlar, e sua importância tende a crescer numa época de crise econômica e escassez de recursos, em que seu gerenciamento adequado é fundamental.

Para sobreviver à globalização e outras questões que influenciam o mercado, o empresário deve estar atento às mudanças, tecnologias e inovações. Quanto mais planejado e controlado é o orçamento e gastos de uma empresa, melhor será sua atuação e durabilidade no mercado.

De acordo com Oliveira (2013), uma boa gestão financeira garante a saúde de sua empresa. Mantendo a liquidez, os compromissos assumidos com terceiros são honrados em dia, além de ampliar seus lucros sobre investimentos. Com o planejamento financeiro não se pretende acertar exatamente valores gastos, mas se preparar para imprevistos do presente e também do futuro.

De acordo com Gitman (1997), o planejamento financeiro é um dos aspectos importantes para funcionamento e sustentação de uma empresa, pois fornece roteiros para dirigir, coordenar e controlar suas ações na consecução de seus objetivos. Dois aspectos-chave são o planejamento de caixa e de lucros. O primeiro envolve o planejamento do orçamento de caixa da empresa; o 
segundo é realizado por meio de demonstrativos financeiros projetados, os quais são úteis para fins de planejamento financeiro interno, bem como exigidos pelos credores atuais e futuros.

De acordo com Harter (2010), o planejamento se faz necessário em todas as atividades da empresa, mas principalmente nas da área financeira, onde os recursos são escassos e os riscos são grandes. Uma gestão financeira eficaz tornou-se atualmente um fator crítico de sucesso. Os administradores das pequenas e médias empresas precisam aprender que as finanças de uma empresa não podem ser administradas de forma intuitiva, nem empírica.

Portanto, diversas análises precisam ser realizadas, e a partir daí, traçar metas, para se ter uma linha lógica a ser seguida, com objetivos concretos e assim sobreviver a concorrência. Além disso, um bom planejamento financeiro deve prever o que ocorrerá caso não aconteça o planejado, não frustrando as expectativas dos empresários. Logo, o objetivo do planejamento financeiro é evitar surpresas e desenvolver planos alternativos.

De acordo com Weston (2000, p. 342), “o planejamento financeiro envolve a realização de projeções de vendas, renda e ativos baseados em estratégias alternativas de produção e de marketing, seguidas pela decisão de como atender às necessidades financeiras previstas".

Gitman (1997, p. 588) afirma que "o processo de planejamento financeiro se inicia com a projeção de planos financeiros a longo prazo, ou estratégicos, que por sua vez direcionam a formulação de planos e orçamentos operacionais a curto prazo".

Sobre planejamento financeiro a longo prazo, Gitman (1997) afirma que os planos são ações projetadas para um futuro distante, acompanhado da previsão de seus reflexos financeiros. Tais planos tendem a cobrir um período de dois a dez anos, sendo comumente encontrados em planos quinquenais que são revistos periodicamente à luz de novas informações significativas. Segundo Silva e Peruzzi (2015, p. 8), o planejamento de longo prazo é parte de um plano estratégico integrado que em conjunto com planos de produção, marketing e outros são utilizados de uma série de premissas e objetivos para orientar a empresa a alcançar seus objetivos estratégicos. Planos como esses são focalizados na dispensa de capital, atividades de pesquisa e desenvolvimento de produtos, estruturas de capitais e importantes fontes de financiamento.

Em relação ao de curto prazo, conforme Gitmann (1997, p. 588) "são ações planejadas para um período curto (um a dois anos) acompanhado da previsão de seus reflexos financeiros". Segundo Silva e Peruzzi (2015), os principais insumos incluem a previsão de vendas e formas de dados operacionais e financeiros, os resultados mais importantes incluem inúmeros orçamentos operacionais, orçamentos de caixa e demonstrações financeiras projetadas.

O planejamento deve acontecer em relação aos investimentos, mas também quanto a gastos físicos, o que inclui contratação de pessoal capacitado, reciclagens e treinamentos, adequando-se sempre as novas tecnologias. Sabe-se que, no mundo corporativo, a concretização dos objetivos e das estratégias organizacionais depende significativamente das pessoas. O capital humano é um elemento fundamental para o sucesso de qualquer empreendimento, pois com trabalho, conhecimento e aprendizado consegue-se inovação e competitividade para se atingir melhores resultados. De acordo com Bernardi (2011 p. 130), "as pessoas são um patrimônio essencial para a empresa, por serem os responsáveis diretos pelo desempenho da empresa".

O planejamento define como as atividades irão acontecer, além de identificar o volume de recursos necessários à sua realização. $\mathrm{O}$ controle ou monitoramento acompanha as atividades em andamento, assegura-se de que elas seguem um determinado plano, identifica e corrige possíveis problemas durante sua execução. Além disso, compara o previsto com o que está sendo realizado; se as metas estão sendo atingidas. A avaliação é o exame das atividades já terminadas, para verificar se elas atingiram as metas fixadas. Estas três funções (planejamento, controle e avaliação) são imprescindíveis para o controle de qualquer negócio. As demais funções podem ser definidas:

- Orçamentação: como o próprio nome já diz, é responsável pela preparação, acompanhamento e execução do orçamento financeiro. 
- Contabilidade: é fundamental, pois registra todas as transações e movimentações de recursos, que envolvam valores monetários, é a "central de informação" da gestão financeira.

- Tesouraria: administra o dinheiro que é mantido em caixa ou em contas bancárias e também cuida de todos os pagamentos e recebimentos.

Já que a maioria das decisões tomadas dentro da empresa é medida em termos financeiros, o administrador da área desempenha um papel chave na empresa. É necessário que os executivos responsáveis nas áreas de contabilidade, produção, pessoal, pesquisa, entre outros, tenham uma compreensão básica da função financeira. Por fim, observa-se que, para que os instrumentos acima mencionados possam contribuir para o sucesso da empresa é necessário à existência de uma liderança ética, positiva, transparente, responsável e comprometida.

A controladoria e o planejamento financeiro e estratégico tem grande importância para manter a empresa ativa e para que as metas estabelecidas sejam atingidas. Atrelada ao controle financeiro deve estar à prática da controladoria como forma de garantir o desempenho em ascensão das organizações, principalmente nos dias atuais, quando o mercado financeiro está volátil por conta das influências externas e internas. Sendo assim, o mercado pede um controller, profissional especialista e generalista. Este tem o papel de planejar estratégias, verificar objetivos traçados e realizados, e assim poderá auxiliar no planejamento financeiro para que a empresa tenha maior índice de êxito e também analisar causas e desvios para sugerir soluções.

O controller precisa divulgar os objetivos, ter visão proativa, ir à busca de informações para trabalhar cenários futuros. Dentro de um ambiente, o controller tem que projetar algum cenário, dar respostas rápidas e eficazes às mudanças impostas pelo ambiente. Com a intensificação da concorrência o mercado exige que a controladoria tenha função essencial para cumprimento da visão. Para que a organização alcance seus objetivos, são de suma importância o entrosamento entre a informação, motivação, coordenação, avaliação, acompanhamento e planejamento do controller. Segundo Gitman (2002, p. 11) "O controller cuida basicamente das atividades contábeis, incluindo administração tributária, informática, contabilidade de custos e contabilidade financeira". Ressalta-se que é um papel contábil, porém deve ser desenvolvido por profissional capacitado e com um conhecimento amplo em: análise de créditos de clientes e fornecedores; fluxo de caixa; contas a pagar e a receber; buscar informações externas.

Essa é a base informacional para o processo de tomada de decisão, visando à implantação de melhorias, além da busca continuamente por atualização e novas soluções. Além disso, o controller precisa estar apto à capacidade de prever os problemas que poderão surgir e coletar as informações necessárias para a tomada de decisões, visando à implantação de melhorias.

Com um lucro fundamentado a empresa pode implantar programas sociais e arcar com esse compromisso, cumprindo a ética e a responsabilidade social que se faz necessário para complementar a função a que se propôs.

\section{CONCLUSÃO}

O Brasil enfrenta hoje uma grande crise financeira, ocasionada pelo aumento de tributos e uma consequente redução na arrecadação, que se agravaram pela descoberta de diversas fontes de corrupção, envolvendo empresários e políticos, o que gerou uma séria crise política, envolvendo deputados, senadores e até mesmo a Presidente da República.

Muitas empresas estão com receio de realizar investimentos, e muitos consumidores com medo de consumir, receosos pela volta da inflação que gerou desvalorização dos salários. É necessário que se faça uma reserva financeira, pois é essencial, não apenas valores a serem investidos e as formas de captação de recursos, mas também os gastos fixos ou variáveis.

O empresário planeja seus gastos e investimentos a curto e longo prazo e aplica suas ações individuais e corporativas de forma que todos sejam incentivados a alcançá-las. 
A empresa deve atuar de forma a oferecer prazer aos que nela laboram, como fonte de manutenção da produtividade. A permanência das empresas no mercado é de suma importância para o país, considerando-se que é medida essencial para que as pessoas possam se desenvolver profissional e pessoalmente, efetivando sua dignidade através do trabalho. Em síntese, o presente trabalho mostrou que o planejamento financeiro é indispensável para a permanência das empresas no mercado.

\section{REFERÊNCIAS BIBLIOGRÁFICAS}

BERNARDI, L. A. Manual de empreendedorismo e gestão: Fundamentos, estratégias e dinâmicas. São Paulo: Atlas, 1011.

CERVO, A. L; BERVIAN, P. A. Metodologia Cientifica. 5 ed. São Paulo: Prentice Hall, 2002.

CHIAVENATO, I. Introdução à teoria geral da administração: uma visão abrangente da moderna administração das organizações. 7. ed. rev. e atual. Rio de Janeiro: Elsevier, 2003.

GITMAN, L. J. Princípios da administração financeira. São Paulo: Habra, 2002.

GITMAN, L. J. Princípios da administração financeira. São Paulo: Habra, 1997.

HÄRTER, L. Planejamento financeiro e orçamento empresarial na comercial de móveis HARTER LTDA. 2010. 70 p. Trabalho de Conclusão de Curso (Bacharel em Administração) - Universidade Federal do Rio Grande do Sul, UFRGS, Porto Alegre, 2010.

LUCION, C. E. R. Planejamento Financeiro. Revista Eletrônica de Contabilidade. Curso de Ciências Contábeis UFSM, v. 1, n. 3, mar-mai/2005.

OLIVEIRA, D. C. Como elaborar controles financeiros. Belo Horizonte: SEBRAE/MG, 2013.

SILVA, A. C.; PERUZZI, M. H. de A. Controladoria e planejamento financeiro. 2015. Curso de Tecnologia em Gestão Financeira. Faculdades Integradas de Três Lagoas - AEMS. Disponível em: <http://www.aems.edu.br/iniciacao-cientifica/download/5971e7ea49.pdf>. Acesso em: 10 jul. 2016.

WESTON, J. F.; BRIGHAM, E. F. Fundamentos da administração financeira. São Paulo: Makron Books, 2000. 